\title{
Marketing Plan Design for Classified Website Based on Big Data
}

\author{
Chenyao $\mathrm{An}^{1}$ \\ ${ }^{1}$ Kang Chiao International School East China, Suzhou, Jiansu Province, P.R. China
}

\begin{abstract}
With the background of big data, it is getting better and better for the marketing environment of classified information websites. Meanwhile, society is progressing, and the traditional marketing model is bound to develop and change, ranging from the beginning of 4P marketing theory (product, price, channel, publicity) to the $4 \mathrm{C}$ marketing theory (customer, cost, convenience, communication) to the current $4 \mathrm{R}$ marketing theory (association, reaction, relationship, remuneration), with different focus on the specific marketing theory. Therefore, this paper presents an active exploration of big data as the core marketing model for classified information websites.
\end{abstract}

\section{INTRODUCTIONADING}

Background-wise, while the application and popularity of China's domestic classified websites is very rapid, there are some bad aspects that accompany the development. Some companies that store data are poorly managed and use platforms to sell users' information, leading to a disaster of data leakage, threats to users' property security and lack of public trust.

Technically, several classified information websites only focus on marketing themselves, more from a pure business perspective to operate, overlooking the technical aspects of the problem. Even if the platform's own moral standards are high and it does not sell the user's data, it is difficult to guarantee that some network hackers use the computer to steal the user's data and then sell it to cause adverse effects. Meanwhile, because of technology is not up to the platform for data mining excavation is too shallow, or some users deliberately do not cooperate, will lead to the authenticity of the data problems, the user image can not be comprehensive enough, there is a certain error, leading to the platform error on the user's analysis, resulting in counterproductive to the website's marketing.

\section{ANALYSIS OF THE MARKETING ENVIRONMENT OF CLASSIFIED WEBSITES BASED ON BIG DATA}

\subsection{Analysis of the external environment of Classified Website Big Data Marketing}

Overall external environment is the political, social, technological and economic environment of the classified website: (1) In national policy, in 2016, the national "13th
Five-Year Plan" put forward the national Big Data strategy to implement big data as a fundamental strategic resource, encouraging enterprises and individuals to drive data to a faster pace. The openness and application of resources are instrumental in promoting the transformation and upgrading of the industry, so within the scope of the law allows the mining, extraction and application of big data is entirely logical and legal, which is supported by the state. (2) Socially and economically, classified information websites possess a large number of potential users. Along with the popularization of networking, people seek opportunities and services on the Internet more often for the sake of life and work, and youth groups are the main body of potential users, who love new things, seek services that are convenient and enjoy the convenience brought by the Internet, and have strong consumption power. Classified sites provide the conditions for big data marketing. (3) Based on the technical level, the continuous development of China's information technology, the renewal of mobile phones, mobile payment has already been applied to the the highways and byways . It could be said that mobile phone has grown into an important medium for people to interact socially. Hence mobile payment in technical aspects gives classified information websites big data marketing to be carried out, mobile phones allow better records of user information and achieve data sharing. (4) Adverse external environment: Cyber hackers are already a pervasive term now in the digital age. By using computer technology, they steal the relevant information stored in the platform and then sell it illegally, which causes severe damages to both users and internet platforms. 


\subsection{Analysis of the internal environment of Classified Website Big Data Marketing}

An internal environment refers to the total sum of the physical and cultural environment of an enterprise. It includes the sum of enterprise resources, enterprise capability and cultural environment. According to the enterprise resources, classified information website doesn't only sell a specific product or offer a specific service, but also provide a variety of local services, such as household management, real estate information, pets, jobs, etc. All of these provide help for the continuous use of users and enable users to increasingly use the classified information website, which is exclusive to the classified information website. Other types of websites do not have the conditions. Besides, in the technical ability of classified information website itself, the rapid development of computer, data storage, analysis and processing have become more and more easy, mostly classified information websites will be equipped with their own database for storing user information, therefore, an accurate grasp of user information can be regarded as half of the marketing success at present. At last, the internal environment also has its disadvantages. Classified information websites such as 58.com, which accounts for one-half of the total amount of classified information websites in the country, have established a definite monopoly, and the monopoly implies that they can dominate advertising and membership fees, not conducive to the overall sustainability of the industry.

\subsection{SWOT Analysis of Classified Website Big Data Marketing}

\begin{tabular}{|c|c|c|}
\hline $\begin{array}{r}\text { External } \\
\text { environment }\end{array}$ & \begin{tabular}{l}
\multicolumn{1}{c}{ Strengths (S) } \\
(1) Website has its own \\
database \\
(2) Possessing a large \\
number of users
\end{tabular} & $\begin{array}{l}\text { Weaknesses (W) } \\
\text { (1) Insufficient funds } \\
\text { (2) Shortage of } \\
\text { technical personnel }\end{array}$ \\
\hline \begin{tabular}{l}
\multicolumn{1}{c}{ Opportunity } \\
$\quad(O)$ \\
(1) A large \\
number of \\
potential users \\
(2) Increasing \\
demand \\
(3) National \\
policy support
\end{tabular} & $\begin{array}{l}\text { In the "13th Five-Year } \\
\text { Plan", the government } \\
\text { takes the implementation } \\
\text { of big data development } \\
\text { and accelerates the } \\
\text { openness and application } \\
\text { of data resources as its } \\
\text { strategic goal. Moreover, } \\
\text { classified information } \\
\text { websites have a steady } \\
\text { user base due to their } \\
\text { large number of services. }\end{array}$ & $\begin{array}{l}\text { It is urgently necessary } \\
\text { to refer the appropriate } \\
\text { personnel who are } \\
\text { skilled in internet } \\
\text { technology and } \\
\text { platform marketing } \\
\text { and promotion to } \\
\text { entice investment from } \\
\text { society and companies } \\
\text { involved, possibly in } \\
\text { the form of dividends } \\
\text { or shares. }\end{array}$ \\
\hline $\begin{array}{l}\quad \text { Risks (T) } \\
\text { (1) Internet } \\
\text { giants dominate } \\
\text { (2) Insufficient } \\
\text { security of } \\
\text { network } \\
\text { environment, } \\
\text { user privacy } \\
\text { leakage }\end{array}$ & $\begin{array}{l}\text { Classified information } \\
\text { websites change their } \\
\text { service focus, make full } \\
\text { use of their features and } \\
\text { apply the state anti- } \\
\text { monopoly law with } \\
\text { technical personnel } \\
\text { management and strict } \\
\text { adherence to user } \\
\text { information }\end{array}$ & $\begin{array}{l}\text { Strengthening human } \\
\text { and financial } \\
\text { investment, collecting } \\
\text { user information and } \\
\text { handling it } \\
\text { confidentially, and } \\
\text { paying attention to } \\
\text { security issues. Several } \\
\text { small and medium- } \\
\text { sized classified } \\
\text { information websites } \\
\text { take full advantage of } \\
\text { funds to bring their } \\
\text { own features into play. }\end{array}$ \\
\hline
\end{tabular}

Figure 1. SWOT Analysis of Classified Website Big Data Marketing
According to the internal and external environment analysis, the SOWT matrix analysis table provides a further analysis of the strengths, weaknesses and opportunities and risks of the big data marketing environment of classifies websites.

Analysis of strengths and opportunities: classification information websites have developed for more than ten years and own a fixed user base. They have sufficient trust in the websites and will visit the classified information websites first to search for relevant solutions, thus offering a mass base for big data marketing. As the Internet is widely popular, so this aspect of the potential users are huge. Besides, there is a great support from the national policies, which makes the development and popularity of big data marketing have no fear of disturbance in the rear.

Analysis of weaknesses and risks: this paper aims to analyze the Chinese classified information websites, which is not a regular business, but an entire industry, besides the large classified information websites such as 58.com and Ganji, almost all cities in China will have their own city information network, therefore it is also essential to guarantee that their big data marketing efforts are carried out. A giant's rise, a dominating force is not beneficial to the industry as a whole in any industry. It is therefore vital to take advantage of advertising and the remittance of local capital to forge your own identity. Followed by network security issues, personal information leakage incidents are common, who should take the responsibility to pay for the interests of user damage at all, absolutely can not avoid the responsibility of the source of information leakage. Insufficient attention to privacy and security issues lead to the tragedy, so the network security issues in a time of big data should be the urgent task of big data marketing to solve the problem.

\section{MARKETING PROCESS DESIGN OF CLASSIFIED INFORMATION WEBSITE BASED ON BIG DATA}

Because the marketing of classified information website is not to sell specific products, but more is a service, so the classified information website needs time and accuracy, to give full play to the website's own value, that is, to timely and accurately transmit effective information to users, including collecting reasonable and effective information from customers, when necessary, to adopt a two-way communication mode, to improve marketing efficiency

The data obtained by the average classifieds site is quite large and cluttered, but a very small percentage of it is really valid information. Therefore, the website should always record the changes in the actual needs of the customers and make corresponding results. Only in this way can it fully improve customer satisfaction and strengthen the user's willingness to use. 


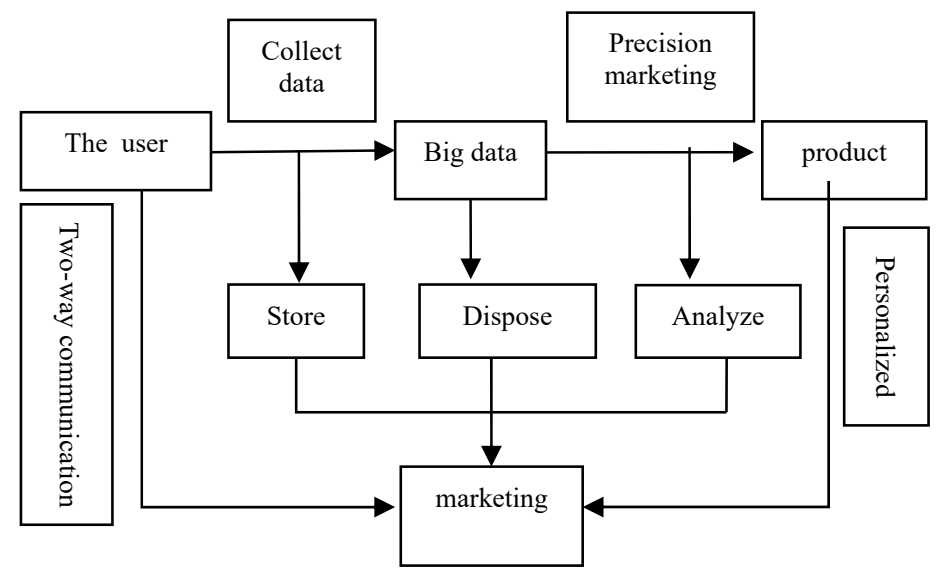

Figure 2: Marketing process of classified information website based on big data

Based on the above, this paper divides the marketing of classified information website into four links: The user Link, the marketing link and the product link are also the platform service link and the big data terminal link. The first is the big data terminal, which is a classifieds site that collects information about users, builds a user portrait, collects the information, as well as deposits it into a huge database. Secondly, for the storage, processing and analysis of big data, it requires the website to analyze these big data, lock in potential target customers, and qualitatively analyze the user's preference from different angles. The third link is precision marketing and personalized customization. In this link, the website has collected the user's data and information and built the user's portrait. Therefore, it is necessary to start to release the user's information and make some measures for the differentiated content generated in it. The last is the marketing link, in this link, the customer's needs and preferences are in constant change, so the website should establish a long-term cooperative relationship with customers, pay full attention to the customer's needs, use relevant technology to analyze the customer's needs in real time, and based on this, design a brand-new marketing relationship mode and carry out accurate marketing.

\section{MARKETING MODE DESIGN OF CLASSIFIED INFORMATION WEBSITE BASED ON BIG DATA}

\subsection{Specific mode of big data marketing of classified information website}

4.1.1 Accurate marketing, customized service: Everyone who registers on the site will choose in advance whether to agree to some of the site's rules and whether to allow the system to locate and access the user's photos, avatars and other conditions, which is a two-way selection mode. If you choose, then the background can access your browsing content and you fill in the age identity and other information, to the user's various attributes for a comprehensive analysis. So as to accurately predict the possible interests and preferences of each person, so that the privacy of the user is not violated, the tracing is carried out to the end, the user is better served, and the time wasted by the user and the unnecessary cost of the website are reduced.

4.1.2 Step by step, one-stop service: Modules on classifieds sites, such as jobs, real estate, used cars, pets, marriage information, etc., may seem unrelated, but they can be combined with the use of big data to bring these seemingly unrelated information together. In today's society, college students are looking for a job is a problem, many people will choose online job search. Some Internet job search platforms can recommend appropriate jobs based on the user's willingness to seek employment. If the user's job search has been answered, the platform will be based on the location of the job applicant recommended rental information, because people get a job after the first thing to solve is the accommodation problem. If the user's accommodation information has been solved online, then the marriage recommendation, pet recommendation can be carried out, so the user will be firmly grasped by the platform.

4.1.3 Grasp the user's purchase behavior and attract users: Generally, the user's cultural level, geographical differences, and income capacity affect the level of consumption and consumption aspirations from the user's side. From the platform aspect, the marketing ability of the platform will have a great impact on the purchase behavior of consumers. Consumer purchasing behaviour is generally divided into five stages. Confirm needs, collect information, evaluate choices, purchase decisions, and evaluate post-purchase consumption effects. This paper argues that big data technology can facilitate user consumption in the following ways. First, confirm the user's needs. The platform can use big data technology to collect user data from various aspects and make accurate recommendations to ensure that the 
recommended products and services are what users need. Secondly, actively provide the content recommendation of relevant complementary products to ensure that users increase their desire for consumption. The next stage is the purchase decision stage, where the key points that will influence the user's thoughts are price and quality. For example, users seek rental information on classified information websites. The traditional ranking method is price or distance, which is a simple way. Users will have a sense of numbness in continuous browsing and affect user experience. However, the use of big data technology in the background through layer-by-layer screening according to the user's network portrait, to the pursuit of novelty young people to recommend simple and fashionable housing, to the elderly to recommend lowlevel, green infrastructure better housing, to some business people to recommend more luxurious decoration, layout more reasonable housing, this can ensure that everyone sees the news is in line with their inner thoughts.

4.1.4 Marketing result feedback:The evaluation of post-purchase consumption effect is mainly about the customer satisfaction after purchase. Because the classified information website has certain differences compared with the traditional purchase behavior of the buyer and the seller, it is difficult to exchange the postpurchase service. At this time, it is necessary for the platform to form a perfect post-purchase evaluation system. The classified information website analyzes the data collected in the marketing process in an all-round way Through Big Data technology, attaches great importance to some common problems of consumers, summarizes relevant experiences and lessons and makes actions to ban some common unreasonable behaviors of users. This has a favorable effect on the secondary marketing of classified information websites and attracting users to continue to use them.

\subsection{Privacy security in the era of big data marketing}

The privacy revelations of Facebook, a leading international social networking site, have been widely debated around the world after the company was exposed in the media that information on some 50 million users of the social networking platform had been accessed and used by a political data company to help the presidential campaign place advertising content to gain user support. Facebook's share price began to plummet that day, and eventually Zuckerberg, the company's founder, had no choice but to apologize to all users in front of the media. In fact, not only Hisense, but also domestic internet giants such as Huawei, tencent and Ali have been caught in the problem of user privacy leakage. With the improvement of National knowledge level, people have begun to pay more and more attention to this aspect. The increasing number of cases of network privacy disclosure has caused a gap between everyone and big data technology.
However, as we all know, technology is a double-edged sword. Privacy issues will inevitably face everyone directly. However, people also enjoy the convenience brought by big data such as service recommendation, unmanned driving, artificial intelligence and so on. How to break this estrangement and bring a sense of security to everyone is not only a problem to be solved by marketing, but also a manifestation of responsibility. The following are the solutions considered in this paper.

4.2.1 At the national level: The arrival of the network era is only more than 20 years, some network security laws are not perfect at the beginning, but with the development of society and the improvement of relevant laws, the network security law is also keeping pace with the times. In the era of governing the country according to law, there are laws to follow, laws must be followed, law enforcement must be strict, and violations of laws must be investigated. Any company or team that steals and sells privacy will be severely punished by the law. Therefore, perfect laws are the fundamental guarantee for protecting privacy and security in the big data era.

4.2.2 For the platform: It is very important to strengthen the technical security level of the database. It is necessary to put an end to the phenomenon of stealing privacy from the network terminal and encrypt and save the user's data. At the same time, it is necessary to train the company's employees, strengthen the professional ethics of the employees, and severely punish the employees who steal the privacy of users and damage the company's image. The platform is the backbone to put an end to privacy disclosure and plays an important supporting role in protecting user privacy and security.

4.2.3 For individuals: It is important to protect their key information, identity cards, bank cards, personal phone numbers and addresses from being given to strangers or online platforms. This is because the official websites do not ask for this information, except for the software used for payment. When filling out the questionnaire online, you should also fill in key information carefully. Be absolutely vigilant about any third-party program. The account password registered on the network should be kept in mind, not easy to disclose to strangers, registration password as far as possible not to be the same as the bank card password. In general, the heart of prevention is indispensable, and the personal aspect is the most important part of network security and privacy protection.

\section{REFERENCES}

1. YY.Ruan, (2020). Research on the organization of network information resources in the $5 \mathrm{G}$ era. Information \& Communications, 206:273-274 
2. K.Xie,J.Wu. (2018) User portrait and user behavior analysis based on big data platform . China Informatization, 03:100-104.

3. XS.Han, X.Lin. (2020) Accurate push classified information publishing platform based on big data. Computer Knowledge and Technology, 16:88-90

4. JW.Xu. (2018) Exploration of online marketing strategy based on big data precision marketing. Private Technology,12:277-278.

5. Yu Jing. (2018) Data mining and application research in the era of big data. Science and Technology and Innovation, 24: 160-161.

6. KIMBLE C , MILOLIDAKIS G . (2015) Big data and business intelligence: debunking the myths[J]. Global Business and Organizational Excellence, 35(1):23-34. 